\title{
NtLRP1, a Tobacco Leucine-Rich Repeat Gene with a Possible Role as a Modulator of the Hypersensitive Response
}

\author{
Alban Jacques, ${ }^{1}$ Ahmed Ghannam, ${ }^{1}$ Mathieu Erhardt, ${ }^{1}$ Patrice de Ruffray, ${ }^{1}$ Fabienne Baillieul, ${ }^{2}$ and \\ Serge Kauffmann ${ }^{1}$ \\ ${ }^{1}$ Institut de Biologie Moléculaire des Plantes du C.N.R.S., Université Louis Pasteur, 12 rue du Général Zimmer, 67084 \\ Strasbourg, France; ${ }^{2}$ Laboratoire de Stress, Défenses et Reproduction des Plantes, Faculté des Sciences, Université \\ de Reims, BP 1039, 51687 Reims, France
}

Submitted 15 November 2005. Accepted 24 February 2006.

Plant defense responses against pathogens often involve the restriction of the pathogen to its site of penetration achieved through the combined effects of the hypersensitive response (HR) and its tightly connected localized acquired resistance (LAR). The tobacco DD9-3 expressed sequence tag was previously isolated from a screen designed to isolate genes induced early during the HR, thus potentially involved in the induction/regulation of the HR or LAR. Translation of the open reading frame of DD9-3 revealed a leucine-rich repeat (LRR) domain highly homologous with the receptor domain of a receptor kinase, suggesting a potential function in signaling pathways. The full-length cDNA was cloned. It encodes a small (232 amino acids) LRR protein, designated Nicotiana tabacum leucine-rich protein 1 (NtLRP1), containing a signal peptide, four leucine zipper repeats, five LRR repeats, and a C-terminal domain rich in proline. NtLRP1 expression is induced early during the HR initiated by elicitins, Ralstonia solanacearum, or Tobacco mosaic virus. NtLRP1 coupled with the green fluorescent protein localizes to the endoplasmic reticulum (ER). Loss-of-function through virus-induced gene silencing or through RNA interference did not modify the elicitin-induced HR or LAR. Gain-offunction experiments through transient Agrobacterium tumefaciens-mediated NtLRPI expression in tobacco leaves caused the suppression of the HR induced by $2 \mathrm{nM}$ elicitin and delayed the HR when the elicitin was applied at higher concentrations. The results suggest that $N t L R P 1$ acts as a modulator of the HR and that retention in the ER is essential for its function.

Additional keyword: cell death.

Strategies developed by plants to defend themselves against pathogens involve restriction of the pathogen to its site of penetration through the combined effects of the hypersensitive response (HR) and localized acquired resistance (LAR) (Dorey et al. 1997; Heath 1998). The HR is a commonly activated resistance process characterized by the rapid induction of localized host cell death. The molecular mechanism involved in the

Corresponding author: S. Kauffmann; Telephone: +33-388 417210; Fax: +33-388 614442; E-mail: serge.kauffmann@ibmp-ulp.u-strasbg.fr

Nucleotide sequence data is available in the GenBank database under accession number DQ118081. execution of the HR is still poorly understood. Only very few genes involved in this process have been functionally characterized (Durrant et al. 2000; Hagihara et al. 2004; Karrer et al. 1998; Lorrain et al. 2004; Marco et al. 1990; Seehaus and Tenhaken 1998; Yamaguchi et al. 2003; Yoda et al. 2002). LAR occurs in the narrow region of living cells surrounding a HR lesion and in which a strong activation of defense responses occurs, contributing to a local, highly inhospitable environment for the invading pathogen. LAR is most often described as the living component of the HR. The HR is induced by exogenous signals issued from the invading pathogen (Keen 1990), whereas LAR is induced by endogenous signals liberated by the cells undergoing the HR (Dorey et al. 1997). Thus, genes early induced during the HR could function either in the execution of the HR or in the induction of LAR.

We recently isolated 24 tobacco expressed sequence tags (EST) characterized by an elicitin-induced HR pattern of expression. Among these, the DD9-3 sequence displays an early and transient expression in HR tissues, and no expression in LAR tissues was observed (Ghannam et al. 2005). Translation of DD9-3 showed a LRR (leucine-rich repeat) domain. LRR defines a versatile protein-binding domain with a motif of 20- to 29-amino acid (aa) residues (Kobe and Kajava 2001). LRRs are usually present in tandem and the number of LRR motifs ranges from one to more than 40 . LRR are found in a functionally and evolutionary diverse set of proteins that apparently share two properties; most LRR-containing proteins appear to be involved in protein-protein interactions, and most of them take part in signal transduction pathways. In plant-pathogen interactions, several plant disease resistance genes that confer the capacity to recognize specific races of plant pathogen and to initiate a defense response encode proteins containing an LRR domain. A large class of $\mathrm{R}$ proteins is located intracellularly and has a nucleotide binding site (NBS)-LRR structure (Belkhadir et al. 2004). Other $\mathrm{R}$ proteins are receptor-like kinases (RLK), such as Xa21 conferring resistance of rice against Xanthomonas pv. oryzae (Song et al. 1995). Others are receptors without the kinase domain, like tomato $C f$ genes. LRR-containing proteins have also been shown to act as receptors of elicitors. For instance, Arabidopsis thaliana FLS2, an RLK protein, recognizes the bacterial protein flagellin (GomezGomez and Boller 2000).

DD9-3 displayed the highest similarity (82\%) at the aminoacid sequence level with the receptor domain of AtSERK1, Arabidopsis thaliana somatic embryogenesis receptor kinase 1 (Hecht et al. 2001). Proteins from the SERK family have been 
implicated in the perception of extracellular ligands via their extracellular LRR receptor domain and the transduction of the signal via the intracellular kinase domain. For instance, BAK1 is implicated in brassinosteroid signal transduction ( $\mathrm{Li}$ et al. 2002). The pattern of DD9-3 expression and the high similarity of DD9-3 with a LRR receptor domain led us to clone the full-length cDNA of the corresponding gene and to design experiments to uncover its function. The gene was designated NtLRP1 (Nicotiana tabacum leucine-rich protein 1). We investigated whether the NtLRPI gene would be induced irrespective of the HR inducer, fungal elicitor, bacteria, or virus and determined the cellular localization of the protein, using various chimeric protein constructs with GFP (green fluorescent protein). We performed gain-of-function experiments through transient Agrobacterium tumefaciens-mediated gene expression and loss-of-function experiments using VIGS (virus-induced gene silencing) and transient $A$. tumefaciens-mediated RNAi (RNA interference).

\section{RESULTS}

\section{NtLRPI cDNA and protein.}

The full-length NtLRP1 cDNA was obtained by RACE PCR (rapid amplification of cDNA ends polymerase chain reaction) cloning. Primers (Table 1) were designed from the DD9-3 EST sequence and were used to perform $3^{\prime}$ and 5' RACE PCR. The template was reverse transcripted from total RNA isolated from tobacco Bright Yellow (BY) cell suspensions treated for 5 $\mathrm{h}$ with a HR dose, $50 \mathrm{nM}$, of $\beta$-megaspermin. Overlapping $5^{\prime}$ and 3 '-end DNA fragments were obtained. New primers (Table 1) were designed to generate by PCR a full-length cDNA clone of NtLRP1. Several full-length clones were obtained, and all showed the same nucleotide sequence.

The NtLRP1 cDNA structure and sequence are depicted in Figure 1. NtLRP1 encodes a 232-aa protein with a molecular mass of 25,110 Da and an isoelectric point of 4.7. Computational analysis highlighted four successive domains, from $\mathrm{N}$ terminus to $\mathrm{C}$-terminus, a putative signal peptide, a leucine zipper (LZ) domain, a LRR domain, and a praline-rich domain

Table 1. Primers used in this study

\begin{tabular}{|c|c|}
\hline NtLRP1 & Primer $5^{\prime}$ to $3^{\prime a}$ \\
\hline 5'RACE & CAAGGATTGACAAGGGTTGG \\
\hline 3' RACE & GGGCAAGCTTCAGAAACTGCGTTTCCTGA \\
\hline CDNA cloning & $\begin{array}{l}\text { (F)GTTGTGGTGAATTGGACTGGGTGG } \\
\text { (R)GGCTCATTTCTTGCCCTAAA }\end{array}$ \\
\hline Expression anal. & $\begin{array}{l}\text { (F)GATCCAACCCTTGTCAATCCTTGTACT } \\
\text { (R)TCGGAGAAATAGGAGGAGGTGGAG }\end{array}$ \\
\hline Position & Cloning primers \\
\hline 24 & (F)ATGGATCAATGGATATTGGGG \\
\hline 109 & (F)AATATTGAAGGTGATGCATTG \\
\hline 234 & (R)TACACTATTCTCACTGTTG \\
\hline 715 & (R)ACCCATAAAAGCATA \\
\hline 718 & (R)TTAACCCATAAAAGCATA \\
\hline 629 & (F)ACTTGCCCTAAAGCAGTCAGC \\
\hline 850 & (R)CTTGCCCTAAAGCAGTCAGC \\
\hline Gene & Primers for gene expression studies \\
\hline EF1 $\alpha$ & $\begin{array}{l}\text { (F)TCGCCTTGTGGAAGTTTGAGAC } \\
\text { (R)CACCAACAGCAACAGTTTGACG }\end{array}$ \\
\hline CCoAOMT & $\begin{array}{l}\text { (F)ATTGGTGTTTTTACTGGTTACT } \\
\text { (R)GCCTTGTTGAGTTCCAATACG }\end{array}$ \\
\hline STC & $\begin{array}{l}\text { (F)TCAAGGTGGTGGAAAGATTTGG } \\
\text { (R)GCTTAGGTATTCAGAAACAGGTG }\end{array}$ \\
\hline PR3b & $\begin{array}{l}\text { (F)CAGGAGGGTATTGCTTTGTTAGGC } \\
\text { (R)ATCTTCCACTGCGTCATTCCGTCC }\end{array}$ \\
\hline GFP & $\begin{array}{l}\text { (F)CGACATGAGTAAAGGAGAAGAAC } \\
\text { (R1)GGTGTACATGAACTTCAGGGTCAGCTTGCC } \\
\text { (R2)TGGTGCACTTCATATTTGTATAGTTCATCC }\end{array}$ \\
\hline
\end{tabular}

$\mathrm{a}(\mathrm{F})=$ forward $(\mathrm{R})=$ reverse that shows no homology with any known domain. A SignalP 3.0 algorithm predicted a signal peptide with a cleavage site after the 28th amino acid. The LZ fits the consensus sequence made by repetition of a group of seven amino acids starting with a leucine, Lxxxxxx (Landschulz et al. 1988). There are four LZ repeats and five LRR repeats (four perfect and one incomplete). Each perfect LRR sequence fulfils the consensus sequence LxxLxxLxLxxNxLSGxIPxxLxx, which belongs to the plant-specific LRR subfamily (Jones and Jones 1997; Kobe and Kajava 2001). The LZ/LRR sequence of NtLRP1 is almost identical $(81 \%)$ to the LZ/LRR sequence of AtSERK1. This suggests that the LZ/LRR structure of NtLRP1 could function as a receptor domain. The extracellular receptor domain of the SERK proteins is linked via a transmembrane domain to an intracellular kinase domain. NtLRP1 lacks both transmembrane and kinase domains. Instead, the C-terminal domain of NtLRP1 is rich in proline, eight prolines between aa 206 and 218. The overall structure of the NtLRP1 cDNA (Fig. 1A) predicts a secreted protein that could interact with other proteins via its LZ/LRR structure.

\section{NtLRP1 expression is induced upon HR triggered by application of a fungal elicitor or inoculation of Ralstonia solanacearum or Tobacco mosaic virus.}

The DD9-3 EST was selected from a screen aimed at identifying genes expressed early upon elicitin-induced HR. We further investigated whether the corresponding NtLRPl gene is expressed early during the HR, irrespective of the HR inducer. We treated tobacco plants with the fungal elicitor $\beta$-megaspermin, with the bacterium $R$. solanacearum or with Tobacco mosaic virus (TMV). We included treatments inducing defense responses without inducing cell death, defined as a defense no death (DND) phenotype. Gene expression was monitored by semiquantitative reverse transcriptase (RT)-PCR, using $E F 1 \alpha$ gene expression to normalize the cDNA template. As molecular markers, we analyzed the expression of typical defenserelated genes, sesquiterpene cyclase $(S T C)$, caffeoyl-CoA $O$ methyltransferase (CCOAOMT), and $P R 3 b$ genes. STC and CCOAOMT are early-induced genes representative of two pathways of secondary metabolism, the sesquiterpenoid and the phenylpropanoid pathways, respectively. The $P R 3 b$ gene is a late-induced gene representative of the $P R$ (pathogenesisrelated) gene family.

Infiltration with $50 \mathrm{nM} \beta$-megaspermin into tobacco plants caused a HR limited to the infiltrated leaf tissues, i.e., no necrotic symptoms beyond the limit of infiltration shown by the black line (Fig. 2A). The narrow region of living cells surrounding the necrotic tissue shows, under UV light, a blue fluorescence due to the accumulation of the phytoalexin scopoletin (Costet et al. 2002). It characterizes LAR. Decreasing 1,000 -fold the concentration of $\beta$-megaspermin did not induce the HR but still induced STC, CCOAOMT, and PR3b genes, characterizing a DND phenotype. $R$. solanacearum GMI1000 induces the HR and LAR, when infiltrated into tobacco leaves as illustrated by the HR cell death and the blue fluorescence under UV light (Fig. 2B). The GMI1525 strain is deleted in the hrp cluster and does not induce the HR but rather triggers a DND phenotype as shown by the induction of STC and CCOAOMT genes (Fig. 2B). To more readily follow changes in NtLRP1 gene expression in tobacco reacting hypersensitively to TMV infection, advantage was taken of the reversible, high temperature inhibition of TMV-induced HR in these plants. At $32^{\circ} \mathrm{C}$, TMV-infected Nicotiana tabacum L cv. Samsun H plants carrying the $N$ gene fail to restrict virus multiplication, spread, or to develop HR lesions. Upon shifting these plants to $22^{\circ} \mathrm{C}$, HR develops rapidly and strongly in a synchronous manner (Fig. 2C). Under these conditions, STC, CCoAOMT, 
and $P R 3 b$ gene expression is rapidly stimulated after the temperature shift (Fig. 2C). Tobacco plants lacking the $N$ gene and treated similarly failed to develop any symptoms and no defense-related genes were induced (Fig. 2C). Whatever the HR treatment, fungal elicitor, bacteria, or virus, NtLRPl expression was found to be induced early (Fig. 2). In contrast, when a DND phenotype was induced using the fungal elicitor at a low concentration or through the infiltration of compatible

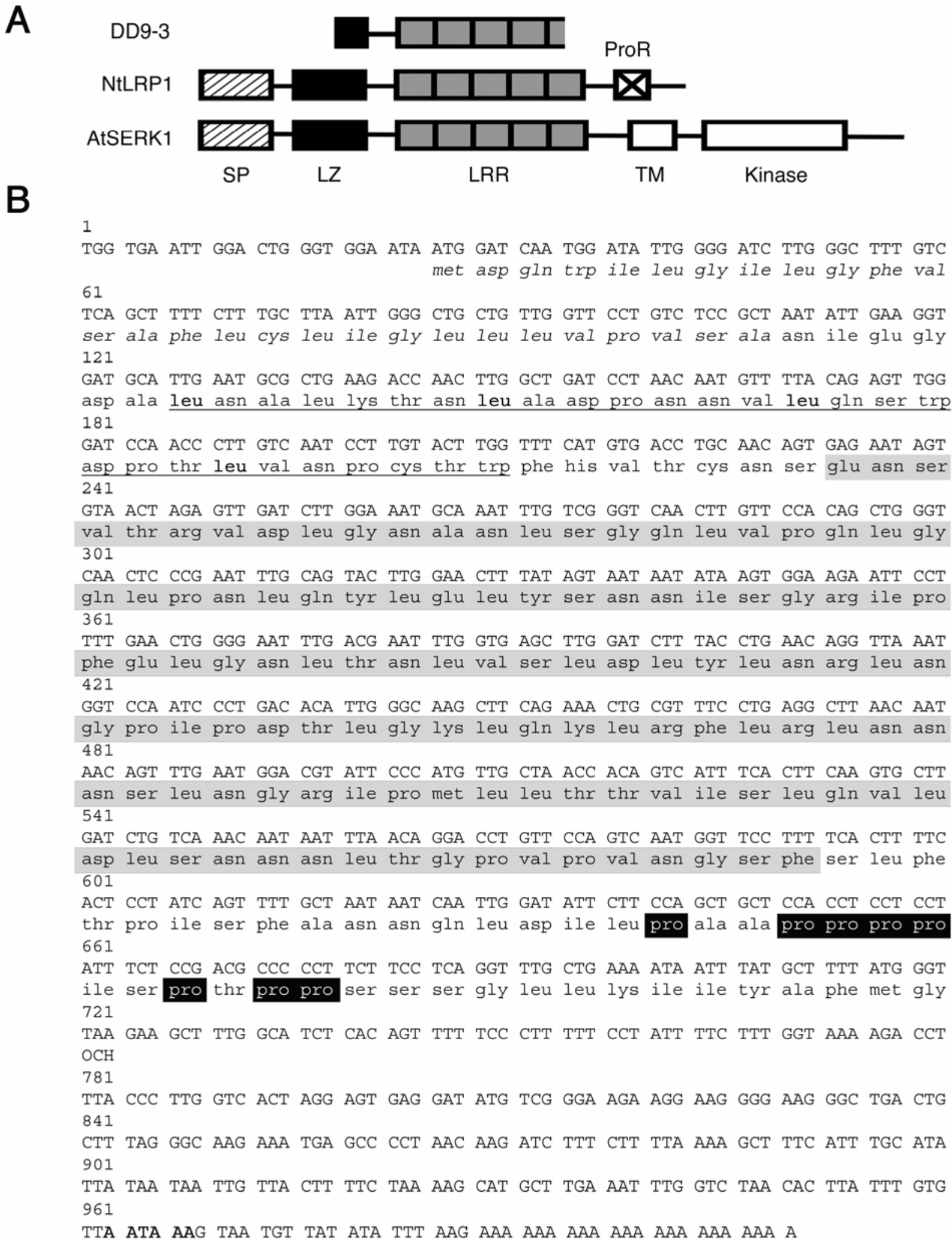

TM

Kinase

B

1

TGg TGA ATt GGA CTG Ggt GgA ATA ATg GAT CAA TGg ATA TTG GGg ATC TTG GgC TTT GTC 61 met asp gln trp ile leu gly ile leu gly phe val

TCA GCT TTT CTT TGC TTA ATT GGG CTG CTG TTG GTT CCT GTC TCC GCT AAT ATT GAA GGT ser ala phe leu cys leu ile gly leu leu leu val pro val ser ala asn ile glu gly 121

GAT GCA TTG AAT GCG CTG AAG ACC AAC TTG GCT GAT CCT AAC AAT GTT TTA CAG AGT TGG asp ala leu asn ala leu lys thr asn leu ala asp pro asn asn val leu gln ser trp 181

GAT CCA ACC CTT GTC AAT CCT TGT ACT TGG TTT CAT GTG ACC TGC AAC AGT GAG AAT AGT asp pro thr leu val asn pro cys thr trp phe his val thr cys asn ser glu asn ser 241

GTA ACT AGA GTT GAT CTT GGA AAT GCA AAT TTG TCG GGT CAA CTT GTT CCA CAg CTG GGT val thr arg val asp leu gly asn ala asn leu ser gly gln leu val pro gln leu gly 301

CAA CTC CCG AAT TTG CAg TAC TTG GAA CTT TAT AGT AAT AAT ATA AGT GGA AGA ATT CCT gln leu pro asn leu gln tyr leu glu leu tyr ser asn asn ile ser gly arg ile pro 361

TTT GAA CTG GGG AAT TTG ACG AAT TTG GTG AGC TTG GAT CTT TAC CTG AAC AGg TTA AAT phe glu leu gly asn leu thr asn leu val ser leu asp leu tyr leu asn arg leu asn 421

GGT CCA ATC CCT GAC ACA TTG GGC AAG CTT CAG AAA CTG CGT TTC CTG AGg CTT AAC AAT gly pro ile pro asp thr leu gly lys leu gln lys leu arg phe leu arg leu asn asn 481

AAC AGT TTG AAT GGA CGT ATT CCC ATG TTG CTA ACC ACA GTC ATT TCA CTT CAA GTG CTT asn ser leu asn gly arg ile pro met leu leu thr thr val ile ser leu gln val leu 541

GAT CTG TCA AAC AAT AAT TTA ACA GGA CCT GTT CCA GTC AAT GGT TCC TTT TCA CTT TTC asp leu ser asn asn asn leu thr gly pro val pro val asn gly ser phe ser leu phe 601

ACT CCT ATC AGT TTT GCT AAT AAT CAA TTG GAT ATT CTT CCA GCT GCT CCA CCT CCT CCT thr pro ile ser phe ala asn asn gln leu asp ile leu pro ala ala pro pro pro pro 661

ATT TCT CCG ACG CCC CCT TCT TCC TCA GGT TTG CTG AAA ATA ATT TAT GCT TTT ATG GGT ile ser pro thr pro pro ser ser ser gly leu leu lys ile ile tyr ala phe met gly 721

TAA GAA GCT TTG GCA TCT CAC AGT TTT TCC CTT TTT CCT ATT TTC TTT GGT AAA AGA CCT $\mathrm{OCH}$

781

TTA CCC TTG GTC ACT AgG Agt GAg GAt Atg tCG GgA AgA Agg AAg gGg AAg ggC tgA CTG 841

CTT TAg GGC AAg AAA tGA GCC CCT AAC AAg ATC TTT CTT tTA AAA GCT tTC ATt tgC AtA 901

TTA TAA TAA TTG TTA CTT TTC TAA AAG CAT GCT TGA AAT TTG GTC TAA CAC TTA TTT GTG 961

TTA ATA AAG TAA TGT TAT ATA TTT AAg AAA AAA AAA AAA AAA AAA AAA A

Fig. 1. NtLRP1 structure and sequence. A, Structure of the DD9-3 fragment, NtLRP1, and AtSERK1 (At1g71830). The structure is based on the amino-acid sequence: SP, signal peptide; LZ, leucine zipper; LRR, leucine rich repeat; TM, transmembrane domain; and ProR, proline-rich domain. B, cDNA sequence and the deduced primary structure of NtLRP1. The amino acids involved in the different structural domains are shown as follows. In italic, those of the putative signal peptide; underlined, those of the LZ domain with the consensus sequence Lxxxxxx.; in gray boxes, those of the LRR domain; and in black boxes, those of the ProR domain. 
bacteria, no early induction of NtLRPl gene was observed, whereas the kinetics of the marker genes CCOAOMT and STC remained unchanged. Additionally, no induced NtLRPI expression occurred in roots, flowers, stems, or leaves of untreated tobacco plants (data not shown).

\section{The chimeric protein NtLRP1::GFP is localized} in the endoplasmic reticulum (ER).

The predicted structure of NtLRP1 suggests the occurrence of a signal peptide. To verify the prediction, we analyzed the localization of different chimeric proteins in tobacco BY-2 cell suspensions as well as in epidermal $N$. benthamiana cells. Three NtLRP1 constructs were tested (Fig. 3A): NtLRP1::GFP, the full-length sequence of NtLRP1 coupled in frame to GFP; TNtLRP1::GFP, a truncated form of NtLRP1 with the signal peptide and the LZ domain coupled in frame to GFP;
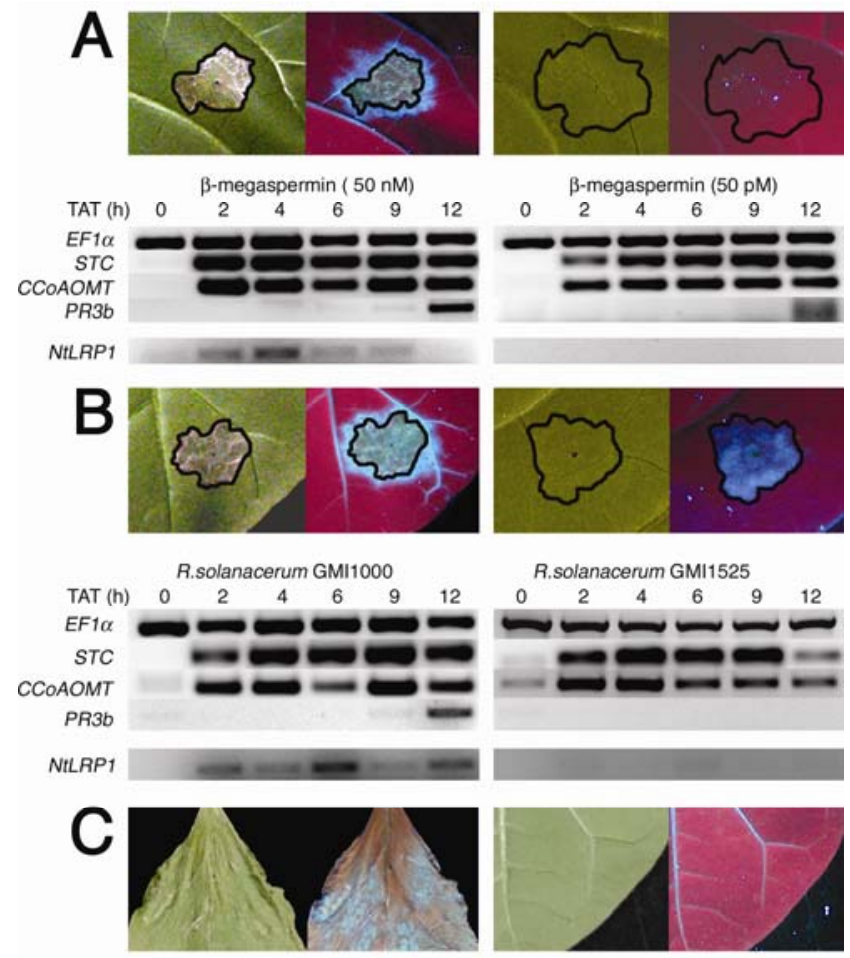

TMV/NN $\mathrm{TMV} / \mathrm{nn}$

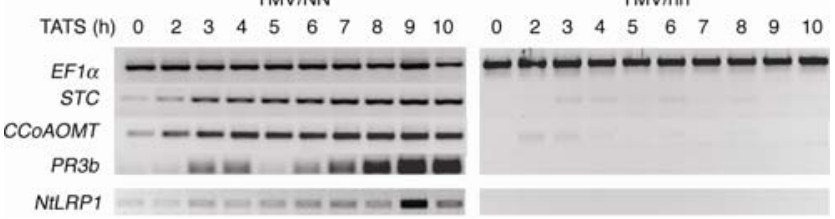

Fig. 2. Expression analysis of the $N t L R P 1$ gene upon fungal elicitor, bacteria, or virus treatment. After the treatments, the tobacco leaf tissues were collected at the different times indicated in hours, and total RNA was extracted to perform semiquantitative reverse transcriptase-polymerase chain reaction normalized with EF1 $\alpha$. Expression of STC, CCOAOMT and $P R 3 b$ was analyzed as control. A, Expression analysis upon fungal elicitor treatment. Tobacco leaves were infiltrated with $50 \mathrm{nM}$ or $50 \mathrm{pM}$ of Phytophthora megasperma $\beta$-megaspermin to induce the hypersensitive response (HR) or defense no death (DND), respectively. B, Expression analysis upon bacterial infection. The tobacco leaves were infiltrated with either Ralstonia solanacearum GMI1000, which induces the HR, or with strain GMI1525, which induces DND. C, Expression analysis upon virus infection. The tobacco plants $N$. tabacum cv. Samsun $\mathrm{H}$, carrying the $N$ gene, and cv. Samsun H, lacking the $N$ gene, were inoculated with Tobacco mosaic virus and were kept at $32^{\circ} \mathrm{C}$ for 3 days. Plants were then shifted to $22^{\circ} \mathrm{C}$, which corresponds to the 0 timepoint, to induce the HR in a synchronous manner. Tissues were collected at different times after the temperature shift (TATS). $\triangle$ SPNtLRP1::GFP, the NtLRP1 sequence lacking the signal peptide sequence coupled in-frame to GFP. Tobacco BY-2 cells and epidermal $N$. benthamiana cells were transiently transformed, and localization of the chimeric proteins was monitored by confocal microscopy.

Transformation of BY-2 cells with the GFP control construct resulted in a cytoplasmic localization of the GFP protein (Fig. 3B), as predicted. On the contrary, TNtLRP1::GFP showed a reticular localization (Fig. 3B). It suggested that the chimeric protein accumulated in the ER, indicating a functional signal peptide. To further demonstrate the ER localization, we transformed BY-2 cells with the construct DsRedKDEL. The DsRedKDEL protein, which contains the ER targeting sequence KDEL, has been demonstrated to localize to the ER (Jach et al. 2001). The merged image clearly shows a colocalization of TNtLRP1::GFP and DsRedKDEL (Fig. 3B). The merged image of GFP and DsRedKDEL (Fig. 3B) indicates, as expected, a distinct localization for GFP and DsRedKDEL. The ER localization of the TNtLRP1::GFP was surprising, as the protein does not contain an ER retention sequence.

To confirm the results, we also transiently transformed epidermal cells of $N$. benthamiana leaves by A. tumefaciens-mediated infiltration (Voinnet et al. 2003). A clear reticular localization was observed in cells expressing NtLRP1::GFP or TNtLRP1::GFP, suggesting an ER localization confirmed with the colocalization with DsRedKDEL (Fig. 3C). $\triangle$ SPNtLRP1:: GFP, the protein deleted of the signal peptide sequence, accumulated in the cytosol (Fig. 3C). It is known that small cytosolic proteins also accumulate in the nucleus. Such nuclear accumulation was observed for $\triangle$ SPNtLRP1::GFP (47 kDa) (Fig. 3C) and not for TNtLRP1:GFP (Fig. 3B) or NtLRP1:GFP (not shown). As expected, DsRedKDEL did not show a nuclear accumulation (Fig. 3B and C). Taken together, the experiments demonstrate that the signal peptide is functional and suggest that NtLRP1 is localized in the ER.

To further test the possibility of a localization of NtLRP1 in the intercellular spaces, we analyzed by transmission electron microscopy Nicotiana tabacum tissues expressing NtLRP1:: GFP after A. tumefaciens-mediated infiltration using antibodies directed against GFP (Fig. 3D). No signal was found in the intercellular spaces. The gold particles occurred only in the ER. More precisely, they were found close to the inner face of the ER membrane and not in the lumen. Thus, both confocal and electron transmission microscopy revealed an ER localization for the chimeric protein in two different Nicotianae species.

\section{Post-transcriptional gene silencing} of the NtLRP1 gene affects neither the HR nor LAR.

The HR pattern of NtLRP1 expression suggests a role in the establishment and execution of the HR or in the induction of LAR. To investigate the possible function of NtLRP1 in the HR or LAR, we analyzed the $\beta$-megaspermin-induced HR in N. tabacum L. cv. Samsun H plants either inoculated with a TMV construct aimed at silencing the NtLRPI gene in the whole plant or infiltrated with A. tumefaciens transformed with a construct aimed at silencing the gene in the infiltrated tissue only. To silence the NtLRPI gene in the whole plant, we used the SVISS protocol (Gossele et al. 2002). The 3' end of the NtLRP1 gene was cloned into pVE350 vector in order to target the $3^{\prime}$ untranslated region of the NtLRPl gene sequence. Plants were infected with TMV strain U2 and Satellite tobacco mosaic virus (STMV) providing the NtLRPI nucleotide sequence. To check for silencing efficiency, we first performed a Northern hybridization to detect siRNA specific for the $N t L R P l$ gene. Figure 4A shows that two out of nine plants accumulated large amounts of the specific NtLRP1 siRNA, indicating that NtLRP1 silencing occurred only in these plants; plant \#2 accumulated 
A
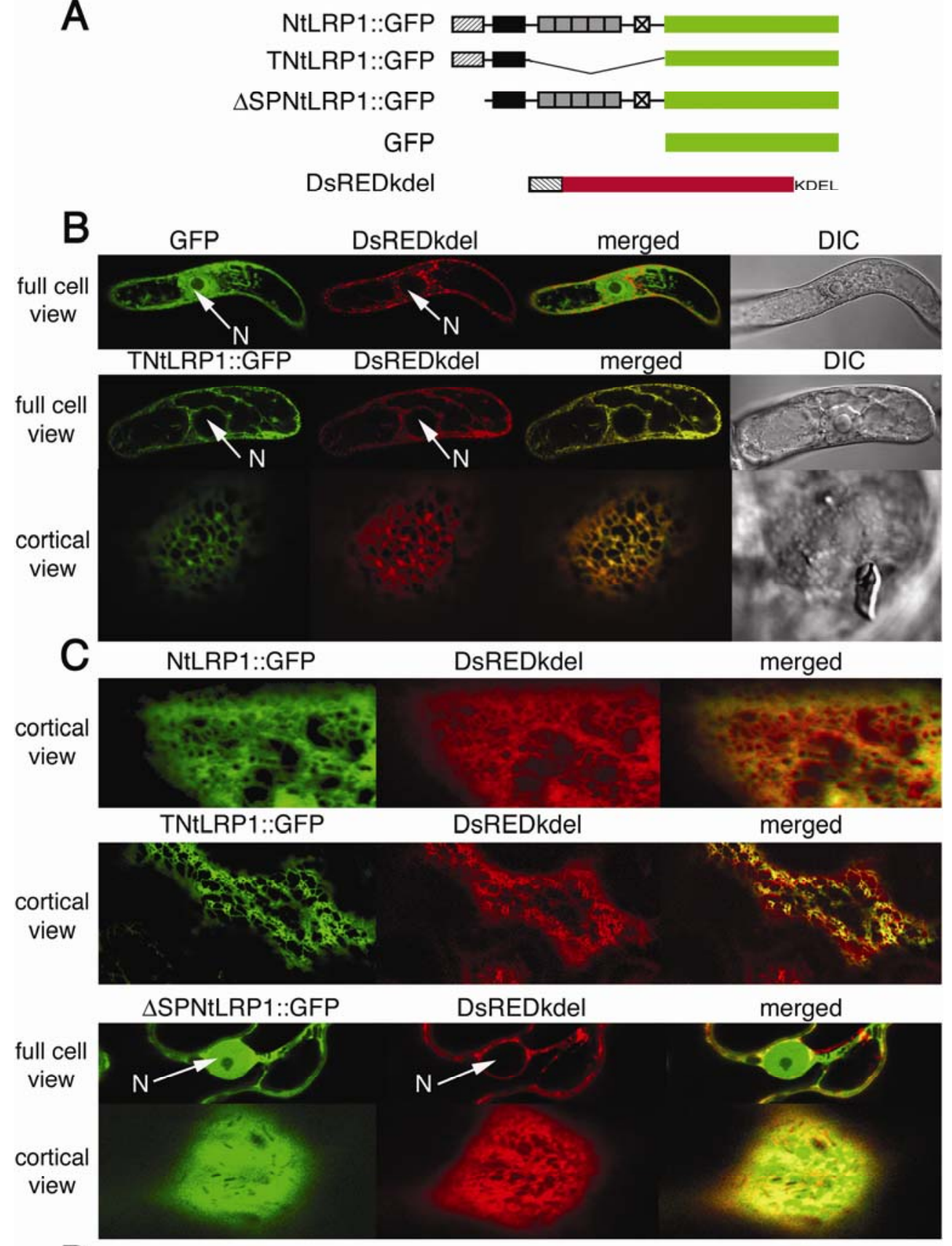

D

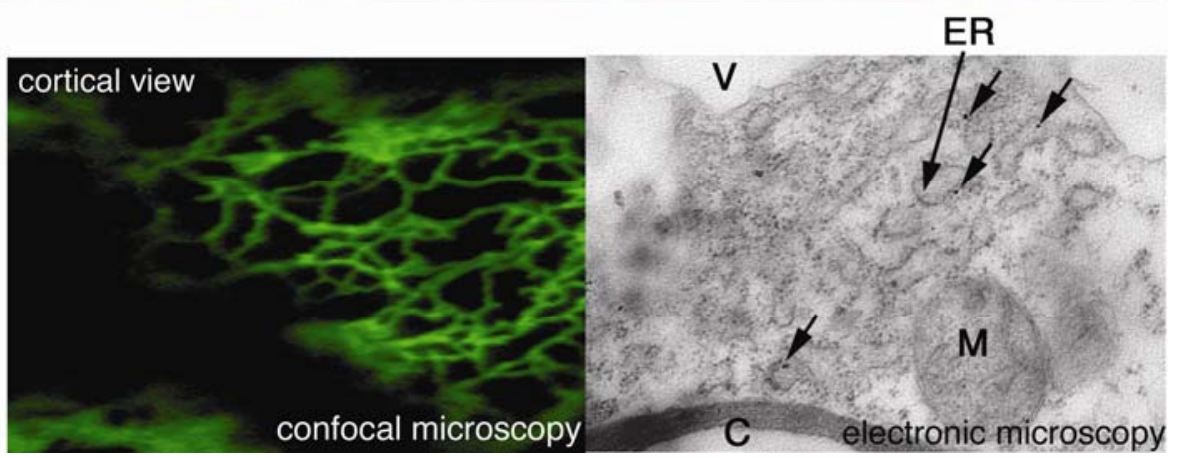

Fig. 3. Cellular localization of NtLRP1. Localization was investigated by confocal and transmission electron microscopy. A, Constructs used for the cellular localization study. The different structural domains are indicated as boxes with different backgrounds. Signal peptide, hatched box; leucine zipper, black box; leucine rich repeat, and gray box. In green, the green fluorescent protein (GFP) sequence and, in red, the DsRedKDEL sequence. B, Localization in BY-2 cell suspensions analyzed by confocal microscopy. The chimeric proteins were transiently expressed in BY-2 tobacco cells. DIC, difference interference contrast. C, Localization in epidermal cells of Nicotiana benthamania analyzed by confocal microscopy. The chimeric proteins were transiently expressed in the epidermal cells using Agrobacterium tumefaciens infection. D, Localization in epidermal cells of Nicotiana tabacum analyzed by confocal microscopy and transmission electron microscopy. The chimeric proteins were transiently expressed in the epidermal cells using A. tumefaciens infection. The short black arrows indicate the gold particles coupled with the GFP antibody. V, vacuole; ER, endoplasmic reticulum; C, chloroplast; and M, mitochondria. 
only very low amounts of these siRNA. Infiltration with $50 \mathrm{nM}$ $\beta$-megaspermin to silenced and nonsilenced plants resulted in the formation of the HR. There was no apparent delay or acceleration of the HR in the silenced plants as compared with the nonsilenced plants. Under UV light, there was no apparent vis-

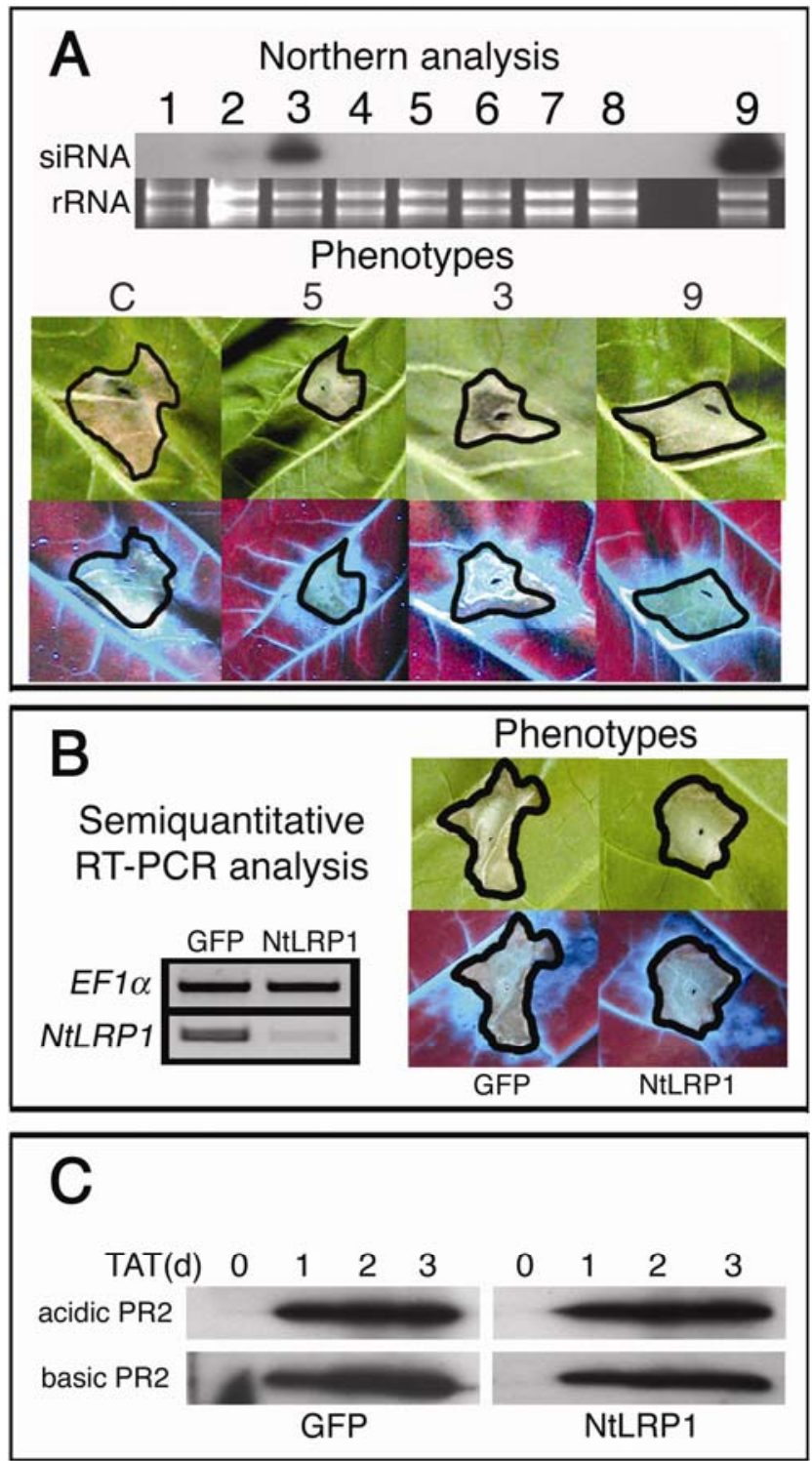

Fig. 4. Post-transcriptional gene silencing (PTGS) of NtLRP1 by SVISS and RNAi. A, PTGS of NtLRP1 by SVISS. Plants, labeled from 1 to 9, were treated via the SVISS method to induce NtLRPI-specific PTGS. To check for PTGS induction, we analyzed by Northern blotting the production of NtLRP1-specific siRNA. Plants were then infiltrated with $50 \mathrm{nM} \beta$-megaspermin 15 days after induction of PTGS. The phenotype of control and of plants 3, 5 and 9 are shown. Pictures under white light (upper row) and under UV light (lower row) were taken two days after elicitor treatments. B, PTGS by RNAi. Tobacco leaves were infiltrated with Agrobacterium tumefaciens transformed with an RNAi construct to induce PTGS specific to NtLRPI (NtLRP1). Controls are plants infiltrated with A. tumefaciens transformed with a green fluorescent protein RNAi construct (GFP). Five days after $A$. $t u-$ mefaciens infiltration, the A. tumefaciens-infiltrated tissue was infiltrated with $50 \mathrm{nM} \beta$-megaspermin, and symptoms were observed under white (upper row) and UV light (lower row). PTGS establishment was checked by analyzing NtLRP1 gene expression by semiquantitative reverse transcriptasepolymerase chain reaction made using RNA extracted $4 \mathrm{~h}$ after $\beta$-megaspermin infiltration. Transcripts were normalized using EF1 $\alpha$. C, Protein gel blot analysis of salicylic acid-dependent acidic PR2 and of ethylene-dependent basic PR2 in localized acquired resistance tissues of RNAi tissues. The tissues showing the blue fluorescence as shown in B were collected to perform the protein gel blot analysis. ual difference in the blue fluorescence, due to scopoletin accumulation, surrounding the HR lesion. Thus, silencing of the NtLRP1 gene had no phenotypic effect on the HR and LAR.

To confirm the results, we also silenced the NtLRPl gene via RNAi (Fig. 4B). By this means, only the tissue infiltrated with transformed A. tumefaciens exhibits silencing of the target gene. Five days after the treatment, silencing efficiency was checked by RT-PCR experiments. Infiltration with $50 \mathrm{nM} \beta$-megaspermin in the tissue previously infiltrated with A. tumefaciens resulted in the establishment of the HR, whatever the construct used. We analyzed the accumulation of the salicylic acid (SA)dependent acidic PR2 protein and the ethylene-dependent basic PR2 protein in the tissue surrounding the HR lesion, to check whether the expression of typical LAR molecular markers was modified. Figure 4C shows a similar accumulation of both acidic and basic PR proteins whatever the construct used. It indicated that silencing of the NtLRPI gene specifically in the HR tissue had no effect on LAR at the molecular level.

\section{Transient expression of the NtLRP1 gene interferes with the $\beta$-megaspermin-induced HR.}

To further investigate the possible function of NtLRPI in the HR or LAR, we infiltrated N. tabacum L. cv. Samsun $H$ leaves with $A$. tumefaciens transformed with different constructs aimed at expressing constitutively the target gene without inducing a post-translational gene silencing (Voinnet et al. 2003). As previously described (Voinnet et al. 2003), the highest level of target protein accumulation occurred five days after A. tumefaciens-mediated infiltration. Six different constructs were made: NtLRP1, NtLRP1::GFP, NtLRP1::Histag, TNtLRP1:: GFP, $\triangle$ SPNtLRP1::GFP, and GFP. Five days after the A. tumefaciens-mediated infiltrations, we measured the expression levels of the different genes and proteins, and then, infiltrated tissues with $\beta$-megaspermin. The infiltration with $\beta$-megaspermin was made so that half of the infiltrated tissue overlapped the site of A. tumefaciens-mediated infiltration and the other half was in tissue that was not previously treated. This second half served as an internal control of HR elicitation.

Gene expression analysis revealed that all the target genes were expressed to relatively high levels in the A. tumefaciensinfiltrated tissues (Fig. 5A). For instance, comparing lane I (NtLRP1 construct) with lane HR (control tobacco tissues expressing the $\mathrm{HR}$ induced by $\beta$-megaspermin infiltration) clearly shows that the $N t L R P 1$ gene was strongly expressed in A. tumefaciens-infiltrated tissues as compared with the expression levels in tissue of control plants exhibiting the HR. We also measured protein levels. Figure 5B shows that the different chimeric proteins accumulated to similar levels. The use of the GFP or the Histag did not change significantly the levels of gene (Fig. 5A) or protein (Fig. 5B) expression. The HR induced by $2 \mathrm{nM} \beta$-megaspermin was suppressed in tissues expressing NtLRP1, NtLRP1::Histag, or NtLRP1::GFP (Fig. 5C). A statistical analysis of at least 40 infiltration sites for each construct revealed that HR suppression occurred in 85 to 95\% of the infiltration sites (Fig. 5D). The presence of the Histag or the GFP sequence did not prevent the phenotype. Three control constructs were tested to confirm this suppression; expression of GFP, of $\triangle$ SPNtLRP1::GFP, and of TNtLRP1:: GFP. GFP and $\triangle$ SPNtLRP1::GFP were shown to accumulate in the cytosol and TNtLRP1::GFP in the ER (Fig. 3). No suppression of the HR occurred in tissues expressing these proteins (Fig. 5C). The result with the $\triangle$ SPNtLRP1::GFP indicated that the deletion of the signal peptide suppressed the activity of NtLRP1 in this test. It suggested that the ER localization was important for NtLRP1 function. The TNtLRP1::GFP control indicated that the accumulation of a chimeric protein in the ER did not cause the suppression phenotype. 
The suppression of the HR was $\beta$-megaspermin dose-dependent. A delay in HR establishment but not suppression occurred when $\beta$-megaspermin was infiltrated at $50 \mathrm{nM}$. The delay was quantified by the increase in conductivity of tissues undergoing the HR (Fig. 6A). The increase in conductivity in tissues A.tumefaciens-infiltrated with the construct NtLRP1 and then treated with $\beta$-megaspermin was less than that occurring in tissues $A$. tumefaciens-infiltrated with the construct TNtLRP1::GFP or GFP. At $12 \mathrm{~h}$ after elicitor infiltration, conductivity in NtLRP1expressing tissues reached the same value as that in TNtLRP1::GFP or GFP tissues. Figure 6B shows that, whatever the concentration of $\beta$-megaspermin between 2 and $50 \mathrm{nM}$, there was the same difference in the electrolyte leakage levels. It can be interpreted as an increased threshold level for HR execution when NtLRPI is transiently expressed. Overall, the results suggest that $N t L R P 1$ acts as a modulator of the HR rather than a suppressor.

\section{DISCUSSION}

The LRR proteins are involved in specific protein-protein interactions and are confined predominantly to eukaryotes
(Kobe and Kajava 2001). The first plant LRR proteins described were receptor serine/threonine kinases and polygalacturonaseinhibiting proteins. In plants, two subfamilies of LRR domains are represented, corresponding to the extracellular plant-specific subfamily and to the intracellular cystein-containing subfamily. The LRR domain of NtLRP1 is structurally related to the plantspecific, extracellular LRR type.

Plant genomes contain genes encoding small proteins, $<400$ aa, that display the SP/(LZ)/LRR/C-terminal domain structure and for which no clear function has yet been demonstrated. Among them, homologs of NtLRP1 were found and analyzed. LeLRP, a tomato 221-aa-long protein, displays the SP/LZ/ LRR/C-terminal domain structure. LeLRP was isolated in an attempt to characterize host cellular factors mediating the response of tomato plants to viroid infection (Tornero et al. 1996). In spite of results suggesting a post-translational regulation induced by the viroid, no clear function for LeLRP could be demonstrated. LeLRP was localized in the extracellular matrix (ECM). A sorghum bicolor cDNA encoding a small LRR protein, SLRR, with an extracellular plant-specific LRR domain was cloned (Hipskind et al. 1996). The 248-aa protein lacks the LZ domain. Only gene-expression studies were de-
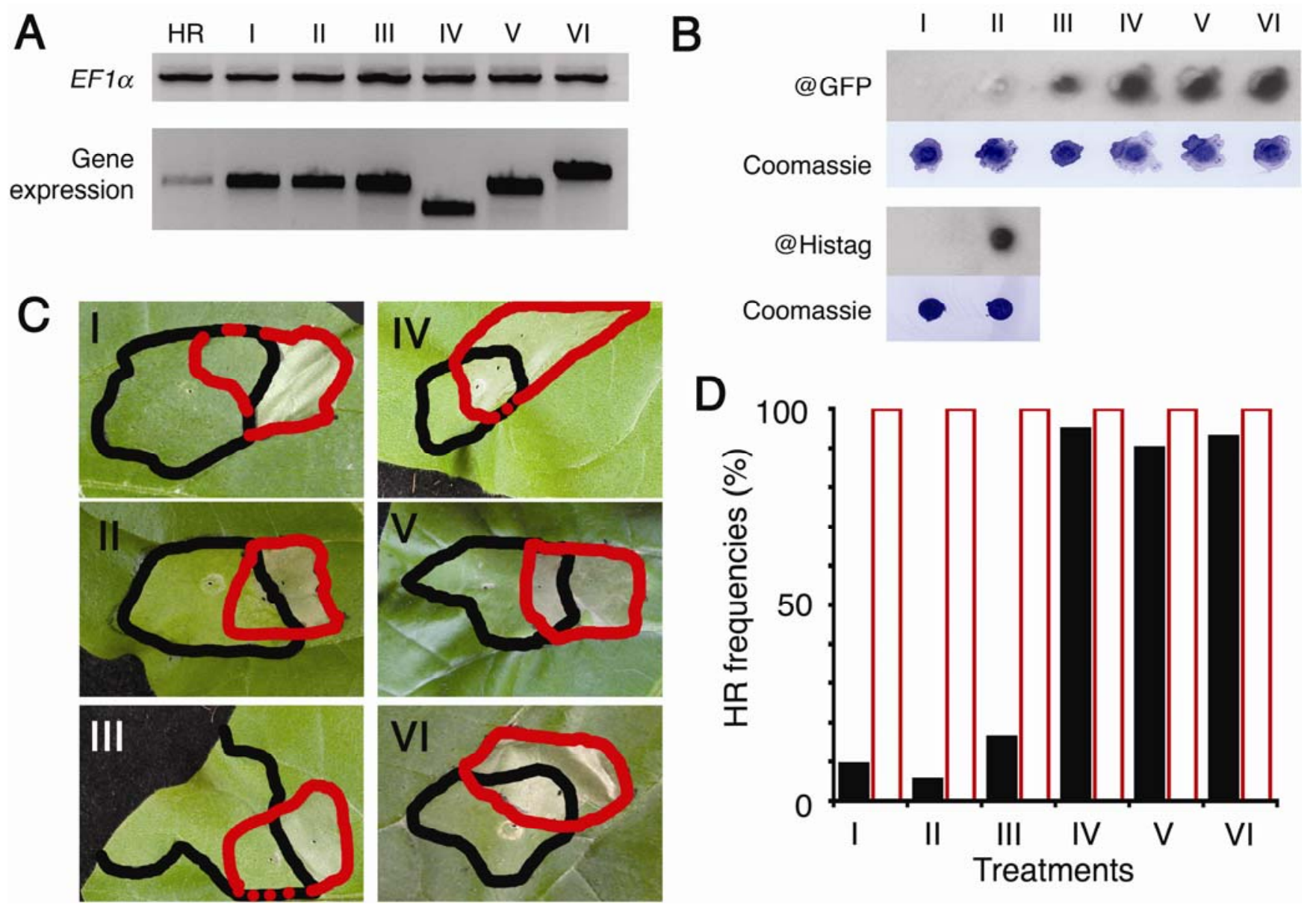

Fig. 5. Agrobacterium tumefaciens-mediated NtLRP1 expression. Tobacco plants were leaf-infiltrated with A. tumefaciens transformed with the following constructs: I, NtLRP1; II, NtLRP1::Histag; III, NtLRP1::GFP; IV, TNtLRP1::GFP; V, $\triangle$ SPNtLRP1::GFP; and VI, and GFP (green fluorescent protein). The infiltrated tissue was delineated with a black pencil. Five days later, $2 \mathrm{nM} \beta$-megaspermin was infiltrated (shown in red) so that half of the infiltrated tissue overlapped with the tissue infiltrated with the A. tumefaciens infiltration site and the other half was beyond this latter site. A, Gene expression analysis by semiquantitative reverse transcriptase-polymerase chain reaction (RT-PCR). The primers used were: for the constructs I, II, III, and V, NtLRP1-specific primers; for the construct IV, the forward primer was specific to NtLRP1 and the reverse primer was specific to GFP; for construct VI, GFP-specific forward and reverse primers. HR shows RT-PCR measuring the endogenous $N t L R P 1$ gene expression from $\beta$-megaspermin-treated tobacco tissues harvested $4 \mathrm{~h}$ after elicitor application. B, Protein levels five days after A. tumefaciens infiltration. The proteins were analyzed by dot blotting using antibodies raised against GFP (@GFP) or against the Histag (@Histag). C, Phenotypes two days after $\beta$-megaspermin infiltration. D, Frequency of the phenotypes observed in the overlapping infiltrated tissues (black bars, A. tumefaciens $+\beta$-megaspermin) and in tissues infiltrated only with $\beta$-megaspermin (white bars with red borders). Each bar results from counting at least 40 infiltration sites issuing from at least 20 plants. 
scribed. The authors show that the gene is induced upon infection with the fungus Colletotrichum graminicola. Antirrhinum majus FIL2 is a 330 -aa protein that lacks the LZ domain (Steinmayr et al. 1994). FIL2 is located in the ECM, as shown by transmission electron microscopy, and was hypothesized to function in flower development. These examples suggest that the small LRR proteins with the PS/(LZ)/LRR/C-terminal domain structure are ubiquitous in the plant kingdom, and the few available results suggest they are involved in plant development and in defense responses against pathogens.

NtLRP1 is the first small LRR protein with a SP/(LZ)/LRR/ $\mathrm{C}$-terminal structure for which gain of function experiments revealed a possible function in the establishment of the HR. Silencing of NtLRP1 by VIGS or by A. tumefaciens-mediated RNAi did not result in visible modifications of the elicitininduced HR and LAR. There is no clear explanation for the lack of phenotype. It suggests that NtLRP1 does not play a crucial role in the establishment of the HR and LAR. Accumulation of acidic SA-dependent and of basic ethylene-dependent PR2 proteins in tissues exhibiting LAR is not modified in NtLRP1-silenced plants through A. tumefaciens-mediated RNAi. Thus, during LAR, induction of SA-dependent and of ethylene-dependent defense responses appeared independent of NtLRP1 expression. It has not been tested whether exogenous application of SA, jasmonate, or ethylene results in NtLRP1 expression. Gain-of-function experiments were performed through A. tumefaciens-mediated transient expression of NtLRP1. Like $R$. solanacearum GMI1525 (Fig. 2B), the Agrobacterium strain induces defense responses when infiltrated into leaf tissues, even when NtLRP1 is expressed. Thus, it is difficult to establish whether the NtLRP1 expression can result in the induction of defense responses in this system. Such activity, although not excluded, is weakly plausible. The conclusion discussed below points to another mode of action for NtLRP1. In the tissues expressing NtLRP1 prior to elicitin application, the HR induced by $2 \mathrm{nM} \beta$-megaspermin was suppressed. Suppression of the HR was also observed in N. benthamiana transiently expressing NtLRP1 and infiltrated with $1 \mu \mathrm{M}$ $\beta$-megaspermin (data not shown). Like $N$. plumbaginifolia (Lecourieux et al. 2002), N. benthamiana plants are less sensitive to elicitins than $N$. tabacum. Nevertheless, the responses induced in $N$. tabacum were reproduced in $N$. benthamiana, using micromolar instead of nanomolar concentrations of $\beta$ megaspermin. The suppression phenotype in $N$. tabacum was elicitin dose-dependent. When $50 \mathrm{nM}$ elicitor was applied, the HR was delayed and LAR remained unaltered. Thus, NtLRP1 would act as a modulator rather than a suppressor of the HR. Dose-response experiments further indicate that the level of NtLRP1 expression would modulate the threshold for HR initiation; increasing the NtLRP1 expression level increases the HR threshold level. The occurrence of a threshold for HR establishment was deduced from the analysis of the Arabidopsis lsdl mutant (Jabs et al. 1996). The molecular mechanism regulating such a threshold level is not clearly understood.

Other genes with function in the HR were described. HSR203J was isolated from a screen to isolate tobacco genes that are induced early during the HR induced by Pseudomonas solanacearum (Marco et al. 1990). HSR203J encodes a putative esterase (Baudoin et al. 1997). Transgenic tobacco plants expressing constitutively an antisense construct of HSR203J display an accelerated HR, suggesting that HSR203J is a negative regulator of the HR (Tronchet et al. 2001). Although expression of NtLRP1 prior to application of elicitin resulted in the suppression or the delay of the elicitin-induced HR, we did not observe accelerated HR in NtLRP1-silenced plants treated with the elicitin. Lesion-mimic mutants of Arabidopsis suggest the existence of genes putatively implicated in HR regulation (Lorrain et al. 2003). For example, LSD1, which is expressed constitutively in wild-type plants and which encodes a zinc-finger protein, was suggested to act as a negative regulator of the HR (Dietrich et al. 1997; Jabs et al. 1996). The Arabidopsis gene VADl encodes a GRAM domain-containing protein. The vadl mutants develop cell death associated with vascular regions of the plant. During the HR induced by Pseudomonas syringae, VADl is strongly expressed in the tissue in the vicinity of the HR lesion (Lorrain et al. 2004). The mode of action of VADl is not known.

NtLRP1 function appears to be directly related to its subcellular localization. Addition of the GFP or Histag sequences to the NtLRP1 sequence did not prevent the suppression of the HR phenotype in protein expression experiments. Transient expression of the chimeric protein deleted of its signal peptide no longer results in the suppression of the HR, indicating that ER localization of the protein is important for the function. The construct, which results in the accumulation in the ER of
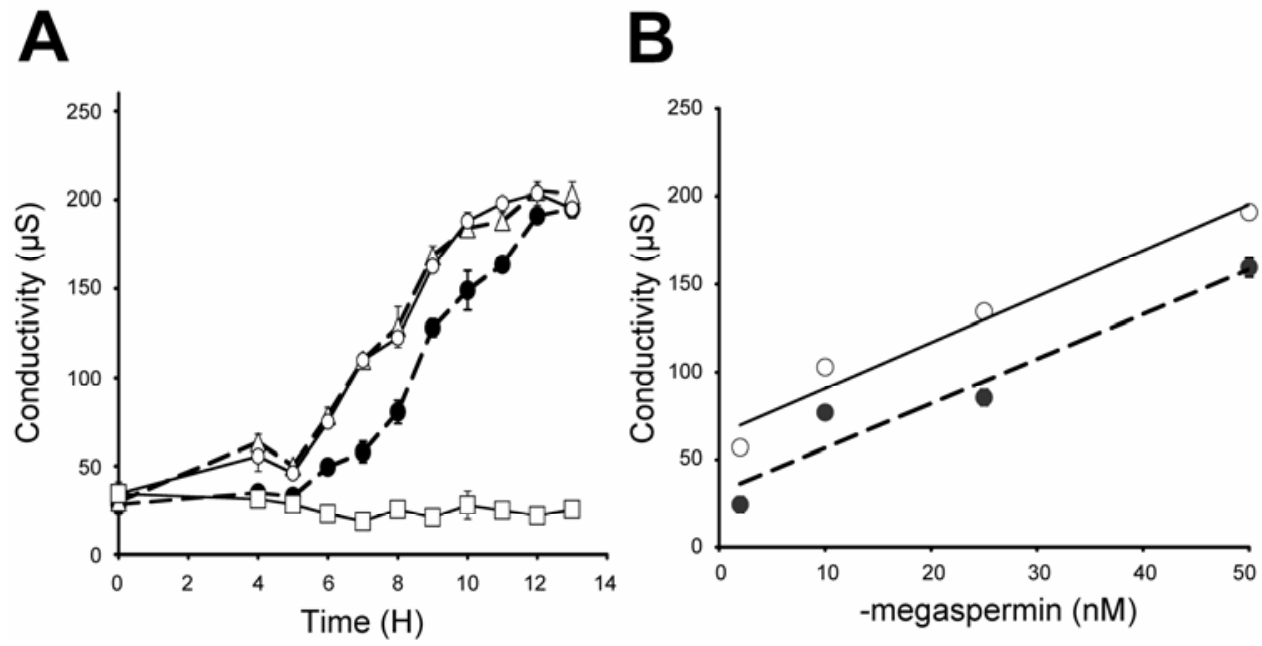

Fig. 6. Monitoring of electrolyte leakage during the hypersensitive response induced by infiltration of $\beta$-megaspermin in tobacco leaf tissues expressing NtLRP1. A, Leaf tissues transiently expressing NtLRP1 (closed circles), TNtLRP1 (open triangles) or green fluorescent protein (GFP) (open circles) through Agrobacterium tumefaciens infiltration were infiltrated with $\beta$-megaspermin. As an internal control, leaf tissues transiently expressing GFP without further $\beta$ megaspermin treatment (open squares) were also analyzed. Electrolyte leakage was measured from leaf disks punched out at different times after treatments. B, Leaf tissues expressing NtLRP1 (closed circles) or GFP (open circles) were infiltrated with different concentrations of $\beta$-megaspermin. Electrolyte leakage was measured from leaf disks punched out $8 \mathrm{~h}$ after treatments. 
the GFP protein bearing the LZ domain in N-terminal, did not lead to the suppression phenotype. This strongly suggests that the accumulation of a chimeric protein into the ER does not by itself cause the suppression phenotype. Consequently, the LRR and possibly the C-terminal domains are required for the function.

The ER localization of NtLRP1 is surprising, because most of the proteins that localize in that compartment display the $\mathrm{K} / \mathrm{HDEL}$ targeting sequence, which is lacking in NtLRP1. However, ETR1, the Arabidopsis ethylene receptor, is one example of a protein lacking the ER targeting sequence but which, nevertheless, has been shown to localize in the ER (Chen et al. 2002). ETR1 does not contain a predicted signal sequence either. It was hypothesized that information for targeting to the secretory system is likely to be contained within the first transmembrane segment of the protein. There is only limited information on sequence determinants for the retention of membrane proteins at the ER, the best known being the cytosolic di-lysine motif $\mathrm{KKXX}-\mathrm{COOH}$ found in type-1 membrane proteins of plants, mammals, and yeast (Benghezal et al. 2000). This sequence is also lacking in ETR1 and NtLRP1, which supports the existence of as-yet-unidentified sequences responsible for ER retention. The LZ domain may fulfill this function in NtLRP1. Indeed, the construct SP/LZ/GFP results in the accumulation of GFP in the ER. However, LeLRP is localized in the ECM, although it discloses an LZ domain highly similar to that of NtLRP1 $(75 \%$ identity, $89 \%$ similarity). The LZ domain has been described to favor dimerization of proteins like transcription factors (Strathmann et al. 2001). Hence, like the LRR domain, the LZ domain allows protein-protein interaction. One hypothesis for the ER retention of NtLRP1::GFP and of the truncated chimeric protein is that the LZ domain would favor an interaction with a protein of the ER. The transmission electron microscopy analysis suggested a localization close to the ER membrane rather than to the ER lumen. There is no predicted anchor hydrophobic domain in the NtLRP1 amino-acid sequence. This leads to the hypothesis that NtLRP1 interacts with a partner anchored to the ER membrane.

In animal cells, the ER participates in the initiation of apoptosis by different mechanisms involving several proteins. IAPs, inhibitors of apoptosis, some of which display an LRR domain, are among the several ER proteins involved in apoptosis regulation. IAPs act as suppressors of apoptosis through the direct inhibition of caspase. No homologs of caspases are known in plants, but some proteases disclose caspase-like activity (Sanmartin et al. 2005), and there are reports indicating activation of caspase activity during the HR (Chichkova et al. 2004). There is another mechanism of apoptosis suppression conserved throughout evolution. It involves a regulator referred to as a Bax inhibitor (BI). A tobacco homolog was cloned, NtBI1 , and was shown to function in human cells (Bolduc et al. 2003). Cell death suppression was not tested in plant cells, however. Localization studies indicate that NtBI-1 localizes to the ER membrane. Oscillations in $\mathrm{ER} \mathrm{Ca}^{2+}$ concentrations take part in the regulation of normal cell function at multiples levels. But perturbations of steady-state $\mathrm{Ca}^{2+}$ levels in the ER as well as acute $\mathrm{Ca}^{2+}$ release can be apoptogenic in animal cells. There are reports showing that $\mathrm{Ca}^{2+}$ channels located on plant ER membranes are involved in plant defense (Blume et al. 2000; Durner et al. 1998; Mithöfer et al. 1999). Particularly, tobacco cells release $\mathrm{Ca}^{2+}$ from the ER upon application of a HR dose of cryptogein (Lecourieux et al. 2002), an elicitin sharing 98\% identity with $\beta$-megaspermin (Baillieul et al. 2003). These few examples indicate that it is highly conceivable that at least part of the regulation mechanisms of the HR involves proteins located in the ER. NtLRP1 could be one of these proteins.

\section{MATERIALS AND METHODS}

\section{Biological materials.}

Nicotiana tabacum L. cv. Samsun H and SR1 and N. benthamiana plants were grown in a greenhouse under controlled conditions. Two to three days before treatments, 4- to 6-week old tobacco plants were placed in a growth chamber at $22 \pm$ $1{ }^{\circ} \mathrm{C}$ with a photoperiod of $16 \mathrm{~h}$. Tobacco cell suspensions, BY2 derived from $N$. tabacum cv. Bright Yellow, were cultured and maintained as described (Costet et al. 1999). The two $R$. solanacearum strains, GMI1000 and GMI1525, used in this study were provided by C. Boucher (Toulouse, France). $\beta$ megaspermin was purified as described earlier (Baillieul et al. 1995). $\beta$-Megaspermin and $R$. solanacearum were applied to the plants by leaf infiltration using a syringe. A solution of 100 $\mu$ of $R$. solanacearum or $\beta$-megaspermin was infiltrated to cover tobacco leaf areas of 3 to $4 \mathrm{~cm}^{2}$ per infiltration spot. For most of the experiments, four infiltration spots per leaf were made. For virus infection, we used the TMV strain U1. TMV was inoculated to tobacco plants using a purified virus solution $(1 \mu \mathrm{g} / \mathrm{ml})$ by rubbing the upper leaf surface in the presence of abrasive celite. Tissues were collected and kept at $-80^{\circ} \mathrm{C}$ until used for RNA extraction.

\section{RT-PCR for NtLRP1 cloning and for semiquantitative expression analysis.}

Total RNA was extracted from tobacco cell suspensions and leaf tissues, using Trizol (Invitrogen, Carlsbad, CA, U.S.A.) according to the protocol supplied by the manufacturer. Total RNA $(2 \mu \mathrm{g})$ were used to perform 5' and 3' RACE (Clontech, Palo Alto, CA, U.S.A.) cloning as described in manufacturer protocols. The primers used for the cloning are given in Table 1. The PCR products were cloned in the pDrive vector (Qiagen, Hilden, Germany). For semiquantitative RT-PCR, first-strand cDNA synthesis was made from $2 \mu \mathrm{g}$ of total RNA. The synthesized cDNA was used as the template for PCR. PCR was performed with denaturing, annealing, and extension temperatures of $94^{\circ} \mathrm{C}$ for $1 \mathrm{~min}, 55^{\circ} \mathrm{C}$ for $1 \mathrm{~min}$, and $72^{\circ} \mathrm{C}$ for $1 \mathrm{~min}$, respectively, for 25 or 30 cycles. Control reactions to normalize RT-PCR amplification were run with EF1 $\alpha$-specific primers (Table 1) and five serial dilutions of each first-strand cDNA template. PCR assays were performed through 25 cycles and resulted in amplification linearly related to RNA amount. Gene-specific primers are listed in Table 1. PCR products were separated on a $1 \%$ agarose gel and were visualized after ethidium bromide staining. Quantification of the PCR products was made in gel, using the Bio-Rad GelDoc apparatus together with Bio-Rad Quantity One software (Bio-Rad, Marnes le Coquette, France).

\section{Vector constructs.}

Thirteen vector constructs were made. For transient expression in BY-2 cell suspensions, we used DsRedKDEL, provided by C. Ritzenthaler (Institut de Biologie Moléculaire des Plantes [IBMP], Strasbourg, France), and NtLRP1 sequence from nucleotides (nt) 24 to 234 ligated in pCK-GFP vector using the NcoI cloning site. For transient expression in N. tabacum and $N$. benthamiana, we used pBin61(GFP), pBin61(p38), and pBin61(p19) provided by O. Voinnet (IBMP). The sequence from nt 24 to 718 of NtLRP1 was introduced in pBin61 vector using $X b a \mathrm{I}$ and Sámi cloning sites. The sequence from nt 24 to 715 of NtLRP1 adding the Histag coding sequence was introduced in the gateway vector $\mathrm{pK} 2 \mathrm{GW} 7$. The NtLRP1 sequences from nt 24 to 234 (TNtLRP1), from nt 85 to 715 ( $\triangle$ SPNtLRP1), and from nt 24 to 715 (NtLRP1) were introduced in the gateway vector $\mathrm{pK} 7 \mathrm{FWG} 2$ to generate TNtLRP1::GFP, $\triangle$ SPNtLRP1:: GFP, and NtLRP1::GFP constructs. For the gateway constructs, 
clones were precluded in the vector pDONR207 (Invitrogen). For the SVISS experiments, we used pVE350 vector (Bayer Crop Science, Manheim am Rein, Germany) with the NtLRPI sequence from nt 629 to 850, using Sufi and Note cloning sites. For the RNAi experiments, we used pFGC5941 vector with NtLRP1 sequence from nt 629 to 850 , and as control, we used pFGC5941 with GFP sequence provided by O. Voinnet. Primers used to clone are shown in Table 1.

\section{Transient expression assays.}

GFP fusion proteins were transiently expressed in BY-2 tobacco cell suspensions. Cells were subculture every seven days and were harvested three days after medium renewal for ballistic bombardment. The harvested cells were filtered onto Whitman disks and were placed on $0.8 \%$ agar Murashige-Skoog media plates supplemented with $0.25 \mathrm{M}$ mannitol for 2 to $4 \mathrm{~h}$. Particle preparation and ballistic assays were performed as described (Vetter et al. 2004). Solutions of A. tumefaciens transformed with vectors of interest were co infiltrated with solutions of $A$. tumefaciens transformed by pBin61(p19) to assay transient expression in $N$. benthamiana or by pBin61(p38) to assay transient expression in $N$. tabacum. The plants were incubated 5 days in a growth chamber at $22 \pm 1{ }^{\circ} \mathrm{C}$ with a photoperiod of $16 \mathrm{~h}$. Tissues were collected for microscopy observation or plants were treated with $\beta$-megaspermin. All constructions were made using the Cauliflower mosaic virus $35 \mathrm{~S}$ promoter.

\section{Confocal and transmission electron microscopy.}

Fluorescent proteins in epidermal cells of $N$. tabacum leaves and in transfected BY-2 cells were visualized by confocal laser scanning microscopy with an LSM510 Zeiss laser scanning confocal microscope equipped with an inverted Zeiss Axiovert $100 \mathrm{M}$ microscope and a $63 \times, 1.2$ water-immersion objective (Zeiss, Le Pecq, France). For each construct, experiments were reproduced at least twice and 30 cells expressing the constructs of interest were observed in each case. No more than $3 \%$ of transfected cells displayed variation of subcellular localization. Such cells were not taken into consideration. Laser scanning was performed using identical settings for singletrack mode and excitation/emission wavelengths of (488/BP 505 to $545 \mathrm{~nm}$ ) for GFP and (543/LP 565) for DsRedKDEL. Image processing was carried out with AIM version 3.2 (Zeiss) and Photoshop 5.5 (Adobe Systems, Seattle). For transmission electron microscopy, leaf tissues were fixed for 1 night in $4 \%$ (vol/vol) glutaraldehyde, $2 \mathrm{~h}$ in $10 \%$ (wt/vol) picric acid, $2 \mathrm{~h}$ in $2 \%$ (wt/vol) uranyl acetate and in $0.1 \%$ (vol/vol) osmium tetroxide in $150 \mathrm{mM}$ sodium phosphate buffer, $\mathrm{pH}$ 7.2. Samples were dehydrated through an ethanol series, were infiltrated with EPON 812 medium grade resin (Polysciences Inc., Niles, IL, U.S.A.), and were polymerized for $48 \mathrm{~h}$ at $60^{\circ} \mathrm{C}$. Ultrathin sections $(90 \mathrm{~nm})$ were cut using an Ultracut E microtome (Reichert, Depew, NY, U.S.A.) and were collected on grids coated with formvar (EMS, Washington, DC, U.S.A.). Immuno-localization of NtLRP1:GFP was performed by incubating the sections with a rabbit anti-GFP antibody (Molecular Probes, Carlsbad, CA, U.S.A.) diluted 1:200 in 1\% bovine serum albumin (BSA) in phosphate buffered saline for $2 \mathrm{~h}$ at room temperature. The secondary goat antirabbit serum was coupled to $15 \mathrm{~nm}$ gold antibody (Aurion EM reagents, EMS) and was applied at 1:50 dilution in $0.1 \%$ BSA for $2 \mathrm{~h}$, followed by washing. Transmission electron microscopy was carried out with a Hitachi H-600 electron microscope at $75 \mathrm{kV}$.

\section{Silencing by SVISS and RNAi and analysis for siRNA.}

Silencing by SVISS was performed as described (Gossele et al. 2002). In vitro transcription was done using RiboMAX T7 (Promega, Madison, WI, U.S.A.). Leaves of N. tabacum L. cv.
SR1 were inoculated with TMV U2 and with $50 \mu \mathrm{g}$ of in vitro transcripted RNA by rubbing the upper leaf surface in the presence of abrasive celite. Upper leaves were collected 15 days after treatment and were kept at $-80^{\circ} \mathrm{C}$; the other leaves were infiltrated with $\beta$-megaspermin. For RNAi, a solution of $A$. $t u$ mefaciens transformed with pFGC5941 vectors was infiltrated into leaves of $N$. tabacum. The plants were incubated five days in a growth chamber at $22 \pm 1^{\circ} \mathrm{C}$ with a photoperiod of $16 \mathrm{~h}$. The A. tumefaciens-infiltrated zones were infiltrated with $\beta$ megaspermin. Prior to $\beta$-megaspermin infiltration, siRNA were analyzed by RNA gel blot analysis of low molecular weight RNA, using $15 \mu \mathrm{g}$ of total RNA as described (Parizotto et al. 2004).

\section{Protein analysis and electrolyte leakage measurements.}

PR protein levels were measured by Western blotting. Protein extraction was performed from 100 to $200 \mathrm{mg}$ of leaf tissues by grinding in $100 \mathrm{mM}$ morpholineethanesulfonic acid (MES) buffer (3:1 buffer/tissue ratio), $\mathrm{pH} 7.5$, containing $15 \mathrm{mM} \beta$ mercaptoethanol and charcoal. The crude extract was centrifuged at $13,000 \mathrm{rpm}$ for $20 \mathrm{~min}$, and the supernatant was used to perform acidic and basic PR protein analysis by protein gel blotting as described (Cordelier et al. 2003). The levels of the different chimeric proteins transiently expressed in $N$. tabacum tissues through A. tumefaciens infiltration were evaluated by dot blot. The tissues were directly crashed onto the immubilon-P membrane (Millipore, Bedford, MA, U.S.A.) using a dot blot apparatus (BRL, Cambridge, U.K.). The membrane was then washed and submitted to Western blotting following the same procedure as the Western blotting of PR proteins, using either antibodies raised against GFP (Molecular Probes) or raised against the Histag (Molecular Probes). For electrolyte leakage measurements, tobacco leaf disks were punched out using a $11-\mathrm{mm}$ diameter cork borer at different times after treatments. Two leaf disks from each treated tissue were placed in $50 \mathrm{ml}$ of water to lower the background signal derived from the wounded cells. Disks were then placed in petri dishes containing $3 \mathrm{ml}$ of fresh water under continuous light at $24^{\circ} \mathrm{C}$ for $20 \mathrm{~h}$. Measurements were taken using a conductivity meter (Horiba twinCond Compact meter B-173; St. Genis Pouilly, France).

\section{ACKNOWLEDGMENTS}

The authors thank O. Voinnet and P. Dunoyer (IBMP) for providing the vectors and the Agrobacterium strains for RNAi and for protein expression, as well as for their advice. We thank also C. Ritzenthaler for providing the vector containing the DsRedKDEL sequence and for helpful discussions on the interpretation of the confocal microscopy results. We are also grateful to M. Metzlaff (Bayer Crop Science) for providing the SVISS system. The Inter-Institute Confocal Microscopy Platform was cofinanced by the Region Alsace, the Centre National de la Recherche Scientifique, the Universite Louis Pasteur, and the Association pour la Recherche sur le Cancer (ARC). The authors are grateful to F. Bernier (Université Louis Pasteur, Strasbourg) for English corrections and also to A. Akers for copyediting the manuscript.

\section{LITERATURE CITED}

Baillieul, F., Genetet, I., Kopp, M., Saindrenan, P., Fritig, B., and Kauffmann, S. 1995. A new elicitor of the hypersensitive response in tobacco: A fungal glycoprotein elicits cell death, expression of defence genes, production of salicylic acid, and induction of systemic acquired resistance. Plant $\mathrm{J}$. 8:551-560.

Baillieul, F., De Ruffray, P., and Kauffmann, S. 2003. Molecular cloning and biological activity of $\alpha-, \beta-$, and $\gamma$-megaspermin, three elicitins secreted by Phytophthora megasperma $\mathrm{H}_{2}$ O. Plant Physiol. 131:155-166.

Baudoin, E., Charpenteau, M., Roby, D., Marco, Y., Ranjeva, R., and Ranty, B. 1997. Functional expression of a tobacco gene related to the serine hydrolase family. Esterase activity towards short-chain dinitrophenyl acylesters. Eur. J. Biochem 248:700-706.

Belkhadir, Y., Subramaniam, R., and Dangl, J. L. 2004. Plant disease resis- 
tance protein signaling: NBS-LRR proteins and their partners. Curr. Opin. Plant Biol. 7:391-399.

Benghezal, M., Wasteneys, G. O., and Jones, D. A. 2000. The C-terminal dilysine motif confers endoplasmic reticulum localization to type I membrane proteins in plants. Plant Cell 12:1179-1201.

Blume, B., Nurnberger, T., Nass, N., and Scheel, D. 2000. Receptor-mediated increase in cytoplasmic free calcium required for activation of pathogen defense in parsley. Plant Cell 12:1425-1440.

Bolduc, N., Ouellet, M., Pitre, F., and Brisson, L. F. 2003. Molecular characterization of two plant BI-1 homologues which suppress Bax-induced apoptosis in human 293 cells. Planta 216:377-386.

Chen, Y. F., Randlett, M. D., Findell, J. L., and Schaller, G. E. 2002. Localization of the ethylene receptor ETR1 to the endoplasmic reticulum of Arabidopsis. J. Biol. Chem. 277:19861-19866.

Chichkova, N. V., Kim, S. H., Titova, E. S., Kalkum, M., Morozov, V. S., Rubtsov, Y. P., Kalinina, N. O., Taliansky, M. E., and Vartapetian, A. B. 2004. A plant caspase-like protease activated during the hypersensitive response. Plant Cell 16:157-171.

Cordelier, S., de Ruffray, P., Fritig, B., and Kauffmann, S. 2003. Biological and molecular comparison between localized and systemic acquired resistance induced in tobacco by a Phytophthora megasperma glycoprotein elicitin. Plant Mol. Biol. 51:109-118.

Costet, L., Cordelier, S., Dorey, S., Baillieul, F., Fritig, B., and Kauffmann, S. 1999. Relationship between localized acquired resistance (LAR) and the hypersensitive response (HR): HR is necessary for LAR to occur and salicylic acid is not sufficient to trigger LAR. Mol. Plant-Microbe Interact. 12:655-662.

Costet, C., Fritig, B., and Kauffmann, S. 2002. Scopoletin expression in elicitor-treated and tobacco mosaic virus infected tobacco plants. Physiol. Plant. 115:228-235.

Dietrich, R. A., Richberg, M. H., Schmidt, R., Dean, C., and Dangl, J. L. 1997. A novel zinc finger protein is encoded by the Arabidopsis LSD1 gene and functions as a negative regulator of plant cell death. Cell 88:685-694

Dorey, S., Baillieul, F., Pierrel, M.-A., Saindrenan, P., Fritig, B., and Kauffmann, S. 1997. Spatial and temporal induction of cell death, defense genes, and accumulation of salicylic acid in tobacco leaves reacting hypersensitively to a fungal glycoprotein elicitor. Mol. PlantMicrobe Interact. 10:646-655.

Durner, J., Wendehenne, D., and Klessig, D. F. 1998. Defense gene induction in tobacco by nitric oxide, cyclic GMP, and cyclic ADP-ribose. Proc. Natl. Acad. Sci. U.S.A. 95:10328-10333.

Durrant, W. E., Rowland, O., Piedras, P., Hammond-Kosack, K. E., and Jones, J. D. 2000. cDNA-AFLP reveals a striking overlap in race-specific resistance and wound response gene expression profiles. Plant Cell 12:963-977.

Ghannam, A., Jacques, A., de Ruffray, P., Baillieul, F., and Kauffmann, S. 2005. Identification of tobacco ESTs with a hypersensitive response (HR)-specific pattern of expression and likely involved in the induction of the HR and/or localized acquired resistance (LAR). Plant Physiol. Biochem. 43:249-259.

Gomez-Gomez, L., and Boller, T. 2000. FLS2: An LRR receptor-like kinase involved in the perception of the bacterial elicitor flagellin in Arabidopsis. Mol Cell 5:1003-1011.

Gossele, V., Fache, I., Meulewaeter, F., Cornelissen, M., and Metzlaff, M 2002. SVISS-A novel transient gene silencing system for gene function discovery and validation in tobacco plants. Plant J. 32:859-866.

Hagihara, T., Hashi, M., Takeuchi, Y., and Yamaoka, N. 2004. Cloning of soybean genes induced during hypersensitive cell death caused by syringolide elicitor. Planta 218:606-614.

Heath, M. C. 1998. Apoptosis, programmed cell death and the hypersensitive response. Eur. J. Plant Pathol. 104:117-124.

Hecht, V., Vielle-Calzada, J. P., Hartog, M. V., Schmidt, E. D., Boutilier, K., Grossniklaus U., and de Vries S. C. 2001. The Arabidopsis SOMATIC EMBRYOGENESIS RECEPTOR KINASE 1 gene is expressed in developing ovules and embryos and enhances embryogenic competence in culture. Plant Physiol. 127:803-816.

Hipskind, J. D., Nicholson, R. L., and Goldsbrough, P. B. 1996. Isolation of a cDNA encoding a novel leucine-rich repeat motif from Sorghum bicolor inoculated with fungi. Mol. Plant-Microbe Interact. 9:819-825.

Jabs, T., Dietrich, R. A., and Dangl, J. L. 1996. Initiation of runaway cell death in an Arabidopsis mutant by extracellular superoxide. Science 273:1853-1856.

Jach, G., Binot, E., Frings, S., Luxa, K., and Schell, J. 2001. Use of red fluorescent protein from Discosoma sp. (dsRED) as a reporter for plant gene expression. Plant J. 28:483-491.

Jones, D. A., and Jones, J. D. G. 1997. The role of leucine-rich repeat proteins in plant defences. Adv. Bot. Res. 24:89-167.
Karrer, E. E., Beachy, R. N., and Holt, C. A. 1998. Cloning of tobacco genes that elicit the hypersensisitive response. Plant Mol. Biol. 36:681-690.

Keen, N. T. 1990. Gene-for-gene complementarity in plant-pathogen interactions. Annu. Rev. Genet. 24:447-463.

Kobe, B., and Kajava, A. V. 2001. The leucine-rich repeat as a protein recognition motif. Curr. Opin. Struct. Biol. 11:725-732.

Landschulz, W. H., Johnson, P. F., and McKnight, S. L. 1988. The leucine zipper: A hypothetical structure common to a new class of DNA binding proteins. Science 240:1759-1764.

Lecourieux, D., Mazars, C., Pauly, N., Ranjeva, R., and Pugin, A. 2002. Analysis and effects of cytosolic free calcium increases in response to elicitors in Nicotiana plumbaginifolia cells. Plant Cell 14:2627-2641.

Li, J., Wen, J., Lease, K. A., Doke, J. T., Tax, F. E., and Walker, J. C. 2002 BAK1, an Arabidopsis LRR receptor-like protein kinase, interacts with BRI1 and modulates brassinosteroid signaling. Cell 110:213-222.

Lorrain, S., Vailleau, F., Balague, C., and Rob,y D. 2003. Lesion mimic mutants: Keys for deciphering cell death and defense pathways in plants? Trends Plant Sci 8:263-271.

Lorrain, S., Lin, B., Auriac, M. C., Kroj, T., Saindrenan, P., Nicole, M., Balague, C., and Roby, D. 2004. Vascular associated death1, a novel GRAM domain-containing protein, is a regulator of cell death and defense responses in vascular tissues. Plant Cell 16:2217-2232.

Marco, Y. J., Ragueh, F., Godiard, L., and Froissard, D. 1990. Transcriptional activation of 2 classes of genes during the hypersensitive reaction of tobacco leaves infiltrated with an incompatible isolate of the phytopathogenic bacterium Pseudomonas solanacearum. Plant Mol. Biol. 15:145-154.

Mithöfer, A., Ebel, J., Bhagwat, A. A., Boller, T., and Neuhaus-Url, G. 1999. Transgenic aequorin monitors cytosolic transients in soybean cells challenged with -glucan or chitin elicitors. Planta 207:566-574.

Parizotto, E. A., Dunoyer, P., Rahm, N., Himber, C., and Voinnet, O. 2004. In vivo investigation of the transcription, processing, endonucleolytic activity, and functional relevance of the spatial distribution of a plant miRNA. Genes Dev. 18:2237-2242.

Sanmartin, M., Jaroszewski, L., Raikhel, N. V., and Rojo, E. 2005. Caspases. Regulating death since the origin of life. Plant Physiol. 137:841-847.

Seehaus, K., and Tenhaken, R. 1998. Cloning of genes by mRNA differential display induced during the hypersensitive reaction of soybean after inoculation with Pseudomonas syringae pv. glycinea. Plant Mol. Biol. 38:1225-1234.

Song ,W. Y., Wang, G. L., Chen, L. L., Kim, H. S., Pi, L. Y., Holsten, T., Gardner, J., Wang, B., Zhai, W. X., Zhu, L. H., Fauquet, C., and Ronald, P. 1995. A receptor kinase-like protein encoded by the rice disease resistance gene, Xa21. Science 270:1804-1806.

Steinmayr, M., Motte, P., Sommer, H., Saedler, H., and Schwarz-Sommer, Z. 1994. FIL2, an extracellular leucine-rich repeat protein, is specifically expressed in Antirrhinum flowers. Plant J. 5:459-467.

Strathmann, A., Kuhlmann, M., Heinekamp, T., and Droge-Laser, W. 2001. BZI-1 specifically heterodimerises with the tobacco bZIP transcription factors BZI-2, BZI-3/TBZF and BZI-4, and is functionally involved in flower development. Plant J 28:397-408

Tornero, P., Mayda, E., Gomez, M. D., Canas, L., Conejero, V., and Vera, P. 1996. Characterization of LRP, a leucine-rich repeat (LRR) protein from tomato plants that is processed during pathogenesis. Plant J. 10:315-330.

Tronchet, M., Ranty, B., Marco, Y., and Roby, D. 2001. HSR203j antisense suppression in tobacco accelerates development of hypersensitive cell death. Plant J. 27:115-127.

Vetter, G., Hily, J. M., Klein, E., Schmidlin, L., Haas, M., Merkle, T., and Gilme,r D. 2004. Nucleo-cytoplasmic shuttling of the beet necrotic yellow vein virus RNA-3-encoded p25 protein. J. Gen. Virol. 85:2459-2469.

Voinnet, O., Rivas, S., Mestre, P., and Baulcombe, D. 2003. An enhanced transient expression system in plants based on suppression of gene silencing by the p19 protein of tomato bushy stunt virus. Plant J. 33:949-956.

Yamaguchi, Y., Yoda, H., Akiyama, K., and Sano, H. 2003. Induction of transcripts encoding a novel seven-transmembrane protein during the hypersensitive response to tobacco mosaic virus infection in tobacco plants Planta 218:249-253.

Yoda, H., Ogawa, M., Yamaguchi, Y., Koizumi, N., Kusano, T., and Sano, H. 2002. Identification of early-responsive genes associated with the hypersensitive response to tobacco mosaic virus and characterization of a WRKY-type transcription factor in tobacco plants. Mol. Genet. Genomics 2067:154-161.

\section{AUTHOR-RECOMMENDED INTERNET RESOURCE}

SignalP 3.0 server: www.cbs.dtu.dk/services/SignalP 